\section{Occupational asthma due to heated freon}

Sir,-I read with interest the report of a case of occupational asthma due to heated freon by Dr J-L Malo and others (August 1984;39:628-9). I recently treated a refrigeration mechanic who developed acute asthmatic symptoms in almost identical circumstances. He had no past history of asthma. His symptoms and clinical signs of airway narrowing gradually resolved over the next 24 hours.

Fluorinated chlorohydrocarbon refrigerants decompose on exposure to a naked flame or hot surface and may evolve highly irritant gases such as hydrochloric acid, chlorine, and phosgene. 'These gases all cause tissue damage in the bronchial tree if inhaled in sufficient concentration. The clinical manifestations of tissue damage are often delayed and, in the case of phosgene, typically occur after a latent period of five to eight hours. ${ }^{2}$ It seems probable that the bronchoconstriction observed by Dr Malo and others in their asthmatic patient was initially a reaction to nonspecific irritation and later a reaction to damage to the bronchial mucosa. The dual reaction can therefore be explained on the basis of mucosal injury without the need to invoke antigenic or other hypersensitivity mechanisms. No reaction would be expected to unheated freon, which does not release these toxic decomposition products.

GB FIELD

Prince of Wales Hospital

Randwick, New South Wales 2031 Australia

' Kern H. Refrigerating plants. In: Parmeggiani L, ed. Encyclopaedia of occupational health and safety. Vol 2. 3rd ed. Geneva: International Labour Office, 1983:1910.

2 Rossmann H. Phosgene. In: Parmeggiani L, ed. Encyclopaedia of occupational health and safety. Vol 2.3rd ed. Geneva: International Labour Office, 1983:1678.

This letter was sent to the authors, and Dr Malo replies below.

Sir,-We are grateful to Dr Field for providing interesting information on the gases which are liberated after the heating of freon. We were also interested to see that Dr Field has encountered a subject with acute asthmatic symptoms after being exposed to heated freon in a similar way to our subject.

We feel that the reaction observed in our subject was not toxic or of an irritant nature and did not cause damage to the bronchial mucosa. Firstly, this patient was not the only person exposed at work to heated freon, yet he was the only one to be affected. It is likely that toxic reactions would have caused similar reactions in other individuals. Secondly, as clearly shown in the figure included in our paper, the late bronchoconstrictive reaction was reversible after administration of a bronchodilator by inhalation. It is unlikely that reaction causing "damage to the bronchial mucosa" would show reversibility after administration of a bronchodilator of the $\beta_{2}$ adrenergic type.

Thus we think it reasonable to exclude a non-specific irritation of the airway in our subject. We think that this case was an example of occupational asthma-namely, asthma caused by a specific, "non-irritant" mechanism at work.

JEAN-LUC MALO

Hôpital du Sacré-Coeur Montreal, Quebec H4J 1C5, Canada

\section{Notices}

\section{Fifteenth World Congress on Diseases of the Chest}

The Fifteenth World Congress on Diseases of the Chest will be held in Sydney, Australia, from 25 to 30 August 1985, under the auspices of the the American College of Chest Physicians and the International Academy of Chest Physicians and Surgeons, in association with the Thoracic Society of Australia and the Cardiac Society of Australia and New Zealand. Major symposia will be presented on cardiopulmonary medicine and surgery, including sessions on cardiopulmonary transplants, hypertension, asthma, occupational lung disease, sleep disorders, exercise physiology, lasers, radiation therapy, trauma, and other subjects. Further information may be obtained from the American College of Chest Physicians, 911 Busse Highway, Park Ridge, Illinois 60068, USA.

\section{Cystic Fibrosis Research Trust}

The Cystic Fibrosis Research Trust honorary medical advisers' conference will be held on 27 September 1985 at the Royal College of Physicians, London. 